\title{
PENDIDIKAN ISLAM DAN DAKWAH PEREMPUAN DI PERKOTAAAN: AISYIYAH JAKARTA SELATAN
}

\author{
Ai Fatimah Nur Fuad \\ Program Studi Pendidikan Agama Islam, Universitas Muhammadiyah Prof. DR. HAMKA \\ Jakarta \\ Email: fatimah_nf@uhamka.ac.id Hp; 081286856829
}

\begin{abstract}
Women's participation in da'wa activities in the community has been widely studied. Likewise with the contribution of their involvement in various da'wa movements or Islamic organizations. This research aims to strengthen the existing studies, with a focus on the Aisyiyah da'wa community in urban areas. Specifically, this research seeks to investigate how inclusive and solutive the da'wa community is in carrying out its various activities among the Ulujami community in South Jakarta. This research was assessed using a qualitative approach that is not only by conducting relevant literature reviews but also by conducting in-depth interviews with leaders and members of the Aisyiyah branch of Ulujami, and the female community who reside and participate in various activities of Aisyiyah Ulujami-South Jakarta. In addition, participant observation were also conducted to look closely variety of their da'wa activities, ranging from religious education for empowering people and strengthening their religiosity to health services for helping people around them. The result of this research conducted in 2019 and early 2020 shows that the variety of activities carried out by Aisyiyah Ulujami in the middle of the Betawi urban community has made significant social contributions, especially in terms of women's empowerment related to strengthening religious insight, awareness to maintain health and strengthening social harmony in the midst of pluralistic society. This research could contribute to the discourses of the activities of female da'wa community in urban areas and its influences to the wider female community and society in general.
\end{abstract}

Keywords: Aisyiyah, Da'wa, Islamic education, Social harmony, Urban society.

\begin{abstract}
Abstrak
Partisipasi perempuan dalam aktifitas dakwah dan pendidikan Islam ditengah masyarakat sudah banyak dikaji. Begitu pula dengan kontribusi keterlibatan mereka dalam berbagai gerakan atau organisasi dakwah. Penelitian ini bermaksud memperkuat kajian yang sudah ada, dengan focus kepada komunitas dakwah Aisyiyah di wilayah perkotaan. Secara khusus, penelitian ini berusaha melakukan investigasi mengenai seberapa inklusif dan solutif komunitas dakwah ini dalam menyelenggarakan berbagai kegiatannya ditengah masyarakat Ulujami di Jakarta. Penelitian ini dikaji dengan menggunakan pendekatan kualitatif yaitu selain dengan melakukan kajian literatur yang relevan juga dengan melakukan wawancara mendalam (in-depth interview) dengan pengurus dan anggota Asiyiyah Ranting Ulujami, serta masyarakat (perempuan) yang bertempat tinggal dan berpartisipasi dalam berbagai kegiatan ranting Aisyiyah Ulujami Jakarta Selatan. Selain itu juga
\end{abstract}


melakukan observasi lapangan (participant observation) melihat dari dekat dan terlibat dalam beragam kegiatan dakwah mereka, mulai dari pendidikan keagamaan untuk permberdayaan masyarakat dan penguatan religiusitas sampai kepada pelayanan kesehatan untuk membantu masyarakat yang membutuhkan. Hasil penelitian yang dilakukan pada tahun 2019 dan awal 2020 ini menunjukkan bahwa ragam aktifitas yang dilakukan Aisyiyah Ulujami ditengah masyarakat urban Betawi telah memberikan kontribusi social yang cukup sifnifikan, terutama dalam hal pemberdayaan perempuan terkait penguatan wawasan Pendidikan keagamaan/keIslaman, kesadaran untuk menjaga kesehatan dan penguatan kerukunan dan harmoni social di tengah masyarakat yang majemuk. Penelitian ini dapat memberikan sumbangsih pemikiran mengenai kontribusi komunitas dakwah perempuan di perkotaan kepada masyarakat luas.

\section{Kata Kunci: Aisyiyah, Dakwah, Pendidikan Islam, Harmoni Sosial, Masyarakat Urban.}

\section{PENDAHULUAN}

Setiap organisasi memiliki visi resmi bagaimana organisasi tersebut akan dijalankan dan kemana akan diarahkan. Biasanya visi ini dikonseptualisasikan, disuarakan, dan disebarkan oleh pimpinannya. Mereka berharap dengan visi resmi ini, organsisasi bisa berjalan efektif seperti yang mereka rancang. Visi resmi tersebut mencakup pola kepemimpinan, sistem rekrutmen anggota dan pola keanggotaan, nilai-dan ideology organisasi, dan lain sebagainya.

Hal ini biasanya difikirkan oleh pimpinan, yaitu mereka yang berada di urutan paling atas dalam sebuah organisasi. Mereka adalah orang-orang yang diamanahi untuk pegang kendali organisasi. Mereka dalam perjalanan kepemimpinannya, tidak hanya mengkonseptualisasikan visinya, tetapi juga mengembangkan dan melakukan transformasi dalam berbagai kegiatan untuk menunjang tercapainya visi organisasi. Mereka juga akan mengembangkan strategi organsisasi dan kegiatan keorganisasian yang berbeda sesuai dengan perubahan konteks social dan politik serta dinamika kesempatan yang datang (opportunities).

Aisyiyah sebagai salahsatu organisasi keagamaan terbesar di Indonesia memiliki visi organisasi, termasuk visi terkait pengembangan aspek dakwah dan pendidikan Islam. Visi ini dibuat oleh pimpinan agar gerakan dakwah dan pendidikan keIslaman yang dilakukan Aisyiyah berjalan efektif dalam membangun dan memberdayakan masyarakat Indonesia. Menjadi organisasi dakwah yang sudah mapan secara usia dan pengalaman, Aisyiyah memikul beban sejarah disatu sisi dan disisi lain menghadapi tantangan dakwah yang makin kompleks seiring dengan makin kompleknya tantangan zaman dan modernitas. 
Salahsatu visinya misalnya adalah melibatkan perempuan dalam berbagai kegiatan dakwah, pendidikan dan social Aisyiyah, merepresantasikan perempuan secara adil dalam berbagai sayap organisasi atau amal usaha yang dipimpinnya dan tidak ada stereotip/bias gender dalam rancangan kegiatan ataupun dalam pelaksanaannya. Pendiri Muhammadiyah yaitu KH. Ahmad Dahlan dan tokoh Muhammadiyah seperti Buya Hamka sudah memberikan contoh perjuangan tentang representasi perempuan yang adil dan luhur, begitu pula tentang kesetaraan gender yang terlihat dalam berbagai kegiatan dakwah, pendidikan dan sosial Muhammadiyah semasa hidup kedua ulama ini. KH Ahmad Dahlan memberi kesempatan dan sangat mendukung istrinya, Nyai Walidah untuk aktif memberdayakan perempuan pada masanya melalui Aisyiyah. Fokus organisasi ini adalah dalam aspek pendidikan untuk memberdayakan perempuan dan mengangkat perempuan ke jenjang yang setara, dimuliakan dan dihargai seperti halnya laki-laki (Fuad, 2020). Begitu juga mendukung istrinya untuk mengembangkan komunitas pengajian perempuan "Sopo Tresno" yang akhirnya menjadi organisasi resmi perempuan bernama Aisyiyah.

Kesempatan, kepercayaan dan dukungan diberikan oleh $\mathrm{KH}$ Ahmad Dahlan kepada perempuan untuk bisa mendapatkan hak-hak yang setara dengan laki-laki. Begitu pula dengan, buya Hamka yang berjuang memberdayakan dan merepresentasikan perempuan secara adil dan menggambarkan perempuan sebagai sosok mulia dalam Islam melalui tulisan-tulisannya di majalah Panji Masyarakat pada tahun 1990-an. Tulisan bersambung tersebut kemudian dibukukan oleh Penerbit Panji Mas pada tahun 1996 dan diterbitkan kembali oleh penerbit Gema Insani Press pada tahun 2014 .

Keteladanan KH Ahmad Dahlan dan Buya Hamka dalam memperlakukan perempuan dan memberinya kepercayaan yang penuh untuk berkiprah dijalan dakwah serta merepresentasikan perempuan secara adil adalah hal baik yang perlu dilanjutkan oleh pimpinan/tokoh Aisyiyah dan Muhammadiyah saat ini dalam mengelola Amal Usaha Muhammadiyah (AUM). Seperti halnya Muhammadiyah, Aisyiyah juga dikenal luas sebagai organisasi perempuan modernis Islam yang memberi kontribusi besar diberbagai bidang seperti bidang dakwah dan bidang pendidikan agama (Ro'fah, 2016). Oleh karena itu, penting melihat bagaimana kiprah perempuan dalam kedua bidang ini di level lapangan, terutama di masyarakat grass root di tingkat ranting.

\section{METODE}

Pertama: Terkait dengan konteks tempat dan wilayah penelitian ini dilakukan, penulis mengumpulkan data dari komunitas Aisyiyah di tingkat ranting. Rasionalisasinya adalah karena mereka yang berada di tingkat ranting seharusnya menjadi front line dalam upaya-upaya memberdayakan masyarakat sekitar lingkungan ranting. Keberadaaan ranting Aisyiyah sangat 
vital dan krusial karena berinteraksi dan berkontribusi langsung kepada masyarakat. Jika programprogram ranting berjalan baik dan dinamis sesuai dengan ideologi yang digariskan oleh organsasi, maka jamaah dan masyarakat akan merasakan manfaatnya dalam perubahan dan perbaikan kondisi dalam masyarakat. Sebaliknya, bila ranting tidak dikelola dengan manajemen baik, maka sumbangsih untuk masyarakat luas juga berkurang atau bahkan tidak ada.

Saya memilih ranting Ulujami-Jakarta Selatan karena beberapa pertimbangan. Seperti pertimbangan pertumbuhan Aisyiyah di Ulujami yang sangat bagus, kegiatan persyarikatan juga sangat beragam dan banyak tidak hanya terkait dengan pendidikan Islam dan dakwah, tetapi juga kesehatan dan amal social lainnya. Selain itu, Ulujami dikenal sebagai kampung Aisyiyah dan Muhammadiyah sejak lama. Maka, mengkaji dinamika pergulatan Aisyiyah di wilayah ini penting untuk bisa menjadi pertimbangan pengembangan dakwah ranting-ranting lainnya. Pertimbangan lainnya adalah karena lokasi penelitian yang cukup dekat dengan kampus sehingga tidak terlalu menyita waktu dan energi. Sehingga proses pengambilan data dalam rentang waktu awal 2019awal 2020 (kurang lebih setahun) seperti yang sudah dijadwalkan bisa berjalan lebih ekektif. Tentu, bisa mendapatkan hasil penelitian yang bermanfaat untuk keilmuan dan penguatan dakwah Aisyiyah, bukan hanya di tingkat ranting tetapi bisa menjadi refleksi di tingkat yang lebih atas.

Kedua, dalam proses pengambilan/pengumpulan data untuk menjawab pertanyaan penelitian ini, digunakan metode kualitatif yang menggabungkan beberapa metode pengambilan data. Selain meneliti literatur/teks tertulis terkait topik diatas, penelitian ini juga menggunakan metode wawancara mendalam, dan observasi lapangan. Terkait dengan metode penelitian yang pertama yaitu review teks tertulis, saya melakukannya dengan cara analisa terhadap konten (content analysis) dan analisa wacana secara kritis (critical discourse analysis) mengenai dinamika gerakan dakwah dan pendidikan perempuan Aisyiyah dalam literatur mengenai Aisyiyah dan literatur mengenai perempuan atau jender.

Pendekatan Critical analysis dan Critical Discourse Analysis ini dipilih untuk membantu memahami dan melakukan analisa konten buku ajar AIKA karena bisa menunjukkan bagaimana sebuah teks membangun realitas social yang secara kontekstual sebetulnya terikat dengan system nilai atau system ideology tertentu melalui pesan-pesan yang disampaikan melalui teks (Widodo, 2018). Selain itu, sebuah wacana dalam teks merupakan sebuah proses sekaligus produk yang diciptakan, embedded dan diinterpretasikan didalam sebuah konteks social tertentu (Halliday, 1978). Oleh karena itu, maka CDA bisa mengungkap bagaimana sebuah system ideology dikonstruksi melalui teks bisa menyingkap nilai-nilai tertentu dalam masyarakat (de los Heros, 2009). Terkait dg reviewe teks ini, saya akan focus untuk melakukan analisa terhadap referensi 
kontemporer yaitu 5-10 tahun terakhir seperti dari artikel jurnal, disertasi dan tesis, dan buku-buku mengenai Aisyiyah untuk mendapatkan informasi teraktual terkait dakwah Aisyiyah dan ragam kegiatan serta dampak sosialnya di tingkat Ranting.

Adapun metode kedua yang penulis pilih untuk melengkapi data yang diperlukan adalah wawancara mendalam. Wawancara dilakukan melalui shilaturrahim mendatangi rumah dakwah Aisyiyah yang berfungsi sebagai sekertariat resmi Asiyiyah dan mendatangi rumah pengurus dan anggota Aisyiyah. Wawancara dilakukan untuk menggali data dan informasi dari anggota Aisyiyah ranting Ulujami Jakarta Selatan. Sementara itu, metode ketiga yaitu observasi bertujuan untuk melihat dan mengamati berbagai kegiatan pendidikan Islam dan dakwah Aisyiyah yang secara rutin sudah dirancang dalam agenda kegiatan Aisyiyah. Selain melihat kegiatan dakwah seperti bakti social, khitanan masal, cek kesehatan dan pengobatan gratis, pengajian, majlis taklim dan lain-lain, observasi juga akan dilakukan dengan cara mengamati perilaku dan pandangan anggota Aisyiyah yang sifatnya informal terkait kegaitan dakwah di lingkungan Ranting Ulujami Jakarta-Selatan (participant observation).

\section{HASIL DAN PEMBAHASAN}

\section{Akar Ideologis Aisyiyah}

Terdapat beberapa literatur tentang dakwah Aisyiyah dalam beberapa tahun terakhir, khususnya 5-10 tahun terakhir. Namun, kuantitas dan fokus dari artikel yang sudah ada masih sangat perlu ditambahkan kajian atau referensi yang menggali tentang gerakan atau praktek dakwah Aisyiyah yang ditinjau dari pengalaman anggota Aisyiyah di tingkat akar rumput (Ranting).

Aisyiyah awalnya merupakan pengajian yang diinisiasi dan dikembangkan oleh istri pendiri Muhammadiyah (KH Ahmad Dahlan), yaitu nyai Walidah. Berdiri sejak tahun 1914 dengan nama pengajian Sopo Tresno atau Sapa Tresna yang artinya siapa Suka atau Siapa Cinta. Nama ini dimaksudkan oleh Nyai Walidah agar perempuan yang mengikuti pengajian ini didorong oleh kesadaran mendalam tentang pentingnya menuntut ilmu dan membekali diri dengan keterampilan. Mereka diharapkan oleh Nyai Walidah tidak datang ke pengajian karena unsur paksaan tetapi didorong oleh rasa suka atau rasa cinta. Nama pengajian tersebut kemudian berubah menjadi Aisyiyah pada tahun 1917. 
Sejak awalnya, Nyai Walidah sangat mendorong anggota pengajiannya dan masyarakat umum untuk terlibat dalam kegiatan kemasyarakatan (Fuad, 2010). Aisyiyah sejak berdirinya sampai saat ini telah memainkan peran penting dalam penguatan kemampuan perempuan Indonesia. Aisyiyah tidak hanya memotivasi perempuan untuk aktif dalam kegiatan pendidikan, dakwah, dan sosial saja, tetapi mendorong untuk aktif memberikan kontribusi kepada negara lewat berbagai peran publiknya. Perempuan didorong oleh Aisyiyah untuk tidak hanya bertanggung jawab dalam ranah domestic, tetapi juga ikut memikirkan dan bertanggung jawab dalam persoalan publik.

Dorongan ini muncul bukan hanya karena kondisi sosiologis perempuan pada masa itu, tetapi bahkan dari kuatnya motivasi ideologis yang dimiliki oleh Nyai Walidah secara individu dan Asiyiyah secara organisatoris (Fuad, 2020). Dengan kiprahnya mendorong perempuan untuk aktif, berilmu dan memiliki keterampilan serta berbagai upaya kesetaraan gender, Nyai Walidah mendapatkan banyak apresiasi dari masyarakat luas dan pemerintah.

Diantara penelitian mengenai Aisyiyah yang sudah ada, Ro'fah (2016) sudah melakukan kajian mengenai posisi dan jatidiri 'Aisyiyah dalam rentang waktu yang sangat panjang, yaitu 1917-1998. Dalam penelitiannya, ia menjelaskan bahwa Aisyiyah memiliki peran yang signifikan dalam pembangunan manusia, baik dalam kehidupan agama ataupun kehidupan sosialnya. Aisyiyah juga memiliki potensi yang sangat besar dalam memberikan gagasan dan pengambilan keputusan selama ada keterwakilan perempuan yang adil di Muhammadiyah.

Selain Ro'fah, Syamsiyatun (2016) menulis perkembangan wacana gender dalam organisasi Nasyiatul 'Aisyiyah tahun 1965-2005. Syamsiyatun menegaskan bahwa Nasyiatul Aisyiyah saat itu bernegosiasi dan beradaptasi dengan kebijakan gender pemerintah. Adapun Dzuhayatin (2015) dalam bukunya "Rezim Gender Muhammadiyah; Kontestasi Gender, Identitas, dan Eksistensi" menjelaskan persoalan gender di Muhammadiyah seperti peran ganda perempuan, relasi laki-laki dan perempuan dalam keluarga, otoritas keagamaan perempuan, hierarki gender, dan lain sebagainya yang terkait dengan gender didalam organisasi Muhammadiyah. Dzuhayatin berargumen bahwa “organisasi social keagamaan merupakan 'strategic agency' berlangsungnya rezimentasi gender dalam masyarakat karena memiliki justifikasi teologis-transendental" (2015: V). Dzuhayatin memilih Muhammadiyah sebagai representasi dari agency diatas.

Fuad (2010) menjelaskan bahwa keterlibatan Aisyiyah di ruang public adalah implementasi dari amar makruf nahyi munkar Muhammadiyah. Ajaran amar makruf ini adalah bentuk kepedulian Aisyiyah untuk menjadi bagian dari upaya memecahkan persoalan social. Sejak 
awal berdirinya, Aisyiyah sangat konsern dalam isu pemberdayaan perempuan. Menurut Fuad, saat ini dengan kondisi masyarakat yang semakin dinamis dan kompleks, Aisyiyah diharapkan bisa terus melanjutkan visi, misi dan pembelaannya terhadap perempuan dan masyarakat, tentu dengan banyak pengembangan dan inovasi baik dalam konsep dan gerakan dakwahnya.

Adapun Dewi (2008) yang menulis kepemimpinan perempuan di Muhammadiyah antara perspektif dan praktek, menggarisbawahi bahwa kepemimpinan perempuan dalam struktur Muhammadiyah belum berhasil karena walaupun gerakan ini berideologi reformis, namun dalam prakteknya masih sulit untuk dilakukan. Selain Dewi, Pranawati (2006) juga menulis tentang kepemimpinan perempuan di Muhammadiyah, yang menurutnya pelibatan perempuan dalam struktur formal sudah ada sejak dulu, tepatnya sejak terpilihnya Prof. Dr. Baroroh Baried walaupun kemudian mundur karena memilih untuk aktif di Aisyiyah.

\section{Perkembangan Historis Aisyiyah Ranting Ulujami}

Walaupun secara organisatoris, Aisyiyah ranting Ulujami Jakarta Selatan baru terbentuk pada tahun 1999, namun jauh sebelum itu, tepatnya akhir tahun 1960-an sudah dimulai aktifitas dakwah para aktifisnya ditengah masyarakat. Aktifitas dakwah --yang menjadi cikal bakal Aisyiyah — dirintis pertama kali di Ulujami oleh Nyak Nin, atau sering juga dipanggil dengan Cing Nin. Cing Nin atau Nyak Nin adalah isteri dari sesepuh Ulujami yaitu KH Syatiri. Pada tahun 1968, aktifitas dakwah Cing Nin ditandai dengan diselenggarakannya pengajian rutin komunitas ibu-ibu Ulujami yang tinggal di sekitar rumah Cing Nin.

Di tahap awal, Nyak Nin menggerakan dan memobilisasi orang-orang terdekatnya, yaitu puteri-puterinya yang bernama $\mathrm{Hj}$ Salmah, Ozah Fauzah, dan cucu-cucu puterinya untuk selalu hadir, terlibat dan menyukseskan pengajian rutin ini. Dengan kontribusi dan mobilisasi yang dilakukan keluarga Nyak Nin ini berjalanlah operasional pengajian Aisiyah. Pengajian Nyak Nin ini diselenggarakan rutin mingguan setiap hari Jum'at. Jamaah atau komunitas ibu-ibu pengajian hari Jum'at pimpinan Nyak Nin KH Syatirih ini kemudian menjadi anggota resmi Aisiyah pada tahun 1968-1972.

Jamaah awal (as-sabiqunal awwalun) dari pengajian Jum'atan ini --yang kemudian menjadi anggota Aisyiyah Ulujami - terdiri dari keluarga terdekat Nyak Nin, tetangga terdekat dan masyarakat yang tinggal sekitar Ulujami. Jemaah awal pengajian Jum'atan yang digerakkan oleh Nyak Nin ini antara lain adalah: Ibu Tati Sarkowi, Ibu Hj Nafsiyah (ibunda Tri Hastuti), ibu Titi (isteri H Didi), Ustadzah Hj Syarkiyah Isa, ibu Hj Salmah binti KH Syatirih, ibu Faozah binti 
KH Syatirih (aktifis Nasyiatul Aisyiyah pada masanya), Isteri Ustadz Ahmad Ardani HS, ibu $\mathrm{Hj}$ Masriyah binti HM, ibu Ruminah binti HM, Ibu Hj Masturoh isteri H Tabri, Ibu Hj Masturoh binti Saobah, Ibu Hj Nyonya H Tafsir, Ibu Mandor J1 Kramat Ulujami, dan masih ada beberapa nama lagi yang turut hadir, menggerakan dan menyemarakkan pengajian ini pada rentang waktu tahun 1968-1972.

Guru pengajian cikal bakal Aisyiyah Ulujami yang pertama kali mengajar adalah ibu $\mathrm{Hj}$ Ummi Dariyah Hamka atau sering dipanggil dengan panggilan Ummi Hamka. Ummi Hamka adalah ibu tiri Prof. Dr. HAMKA (Haji Abdul Malik Karim Amrullah)-seorang ulama ilmuwan yang menulis Tafsir karya monumentalnya yaitu Al-Azhar--. Pada tahun 1968-1972, Ummi Hamka bergantian mengajar dengan KH Syatiri semasa hidupnya. Kemudian sejak wafatnya KH Syatiri pada tahun 1993, Ummi Hamka mengajar bergantian dengan Ustadz Ahmad Ardani HS.

Adapun guru pengajian Jum'atan--cikal bakal Aisyiyah Ulujami-yang kedua adalah Ibu Hj Sahi dan Ust Ahmad Ardani HS (1993). Sementara, guru pengajian ketiga adalah ibu Hj Rachmi atau yang lebih dikenal dengan ibu Nasrun dan ustadz Ahmad Badawi Hasya yaitu pada tahun 1993 sampai 2009. Sejak tahun 2009, karena ustadz H. Ahmad Badawi Hasya meninggal dunia, maka kemudian guru mengaji Aisyiyah Ulujami yaitu Ibu Hj Rachmi (Bu Nasrun), didampingi oleh guru pendamping yang baru yaitu ustadz Ahmad Najihan Maududi, MA (alumni Pesantren Gontor yang merupakan menantu dari H. Badawi Hasya). Ibu Nasrun dan ustadz Najihan mulai tahun 2009 sampai sekarang, merupakan orang yang diberi amanah dan tanggung jawab dalam memberikan wawasan agama atau tausyiah kepada ibu-ibu anggota pengajian Jum'atan.

Ketua Aisyiyah ranting Ulujami yang pertama adalah $\mathrm{Hj}$. Rusteni. Beliau merupakan istri dari pendiri Muhammadiyah ranting Ulujami yaitu H. Agus (Lihat Fuad, 2018). Ibu Hj. Rusteni menuturkan awal-awal perjuangan mendirikan ranting Aisyiyah di Ulujami pada waktu itu:

"Aktivitas Aisiyah Ulujami bermula ketika bapak (H. Agus) dan rekan-rekannya hendak menggerakkan kegiatan-kegiatan Muhammadiyah dan Aisiyah di sekitar Ulujami. Mereka berfikir bagaimana cara menggerakannya karena akan banyak membutuhkan dukungan finansial. Pada awalnya, mereka belum mendapatkan banyak simpati masyarakat yang mengulurkan bantuan pendanaan itu [untuk menggerakan ranting]. Namun H. Agus dkk jalan terus [dengan berbagai kegiatan dakwah, pendidikan, dan sosial]".

Menurut Hj. Rusteni, suaminya H Agus merintis dan memimpin organisasi massa keagamaan Muhammadiyah Ranting Ulujami ini melalui H Rohmani H Sidik Mun yang waktu itu tinggal di Jl. H. Ridi RT 002/03 Ulujami pada tahun 1998. 
Adapun seluruh kegiatan Aisyiyah saat ini terpusat pelaksanaannya di gedung Dakwah Aisyiyah (Muhammadiyah) yang berada di Jl. Swadarma Raya RT 02/3 Ulujami Pesanggrahan Jakarta Selatan 12250. Kegiatan pengajian rutin, cek kesehatan masal dan pengobatan gratis, serta pendidikan agama Islam untuk seluruh rentang usia (kanak-kanak, remaja, orangtua) dilaksanakan di gedung dakwah Aisyiyah ini. Gedung ini merupakan wakaf dari keluarga H. Agus, yang merupakan mertua dari Menteri Agama periode sebelumnya, Lukman Hakim Saifuddin.

\section{Inklusifitas Kegiatan Dakwah Perempuan}

Kegiatan dakwah Aisyiyah meliputi bidang pendidikan, kesehatan, dan social, dan lainlain. Ketiga bidang ini sangat menonjol dan merupakan kegiatan utama Asiyiyah ditengah masyarakat Ulujami Jakarta Selatan. Kegiatan pendidikan keagamaan sendiri sangat beragam aktifitasnya darimulai kegiatan pengajian Majlis Taklim khusus ibu-ibu sampai kegiatan Baca Tulis Al-Qur'an (BTQ), yang menyasar semua usia; mulai ibu-ibu, remaja dan anak-anak.

Selain itu, ada juga kegiatan pengkaderan Nasyiatul Aisyiyah (NA) yang saat ini merupakan aktivitas utama Aisyiyah selain pengajian. Pengajian dilaksanakan setiap Sabtu kedua setiap bulan bertempat di Gedung Dakwah Aisyiyah Ulujami. Adapun pengajian Al-Muthmainnah yang masih di bawah bimbingan Aisyiyah Ulujami, jadwal mengajinya setiap Hari Minggu.

Kegiatan pendidikan Islam atau penguatan keagamaan ini dilakukan secara bergilir, ada yang khusus pas libur Sabtu-Minggu (weekend) seperti dua pengajian/majlis taklim diatas ada pula yang hari kerja (weekdays), ada yang diselenggarakan pagi hari, ada juga yang siang atau sore hari. Semuanya diselenggarakan dengan kesepakatan bersama setiap grup pengajian/kajian/kursus BTQ, dengan tujuan agar anggota dan jamaah sekitar bisa lebih banyak yang hadir dengan pertimbangan kesibukan yang dimiliki masing-masing. Bagi jamaah yang memiliki kesibukan lain di pagi hari, Aisyiyah memfasilitasi mereka dalam pengajian sore atau malam hari. Begitupula sebaliknya.

Ada pula kegiatan kesehatan yang mencakup konsultasi kesehatan, check-up kesehatan dan pemberian obat gratis kepada masyarakat sekitar Ulujami. Kegiatan dakwah dibidang kesehatan ini dilakukan dengan cara mengundang dan melibatkan dokter kesehatan dan ahli obat untuk datang secara rutin ke sekretariat dakwah Aisyiyah di Jl. Swadarma Ulujami. Layanan kesehatan yang lain dan sudah rutin dilakukan adalah khitanan masal, terutama anak-anak yang sudah cukup usia untuk khitan tetapi belum dilakukan karena keterbatasan finansial orangtuanya. Jika selama ini pengurus Aisyiyah hanya menyalurkan anak-anak yang mau khitan ke Masjid Bintaro atau 
masjid Pondok Gede untuk bersama-sama disunat dengan khitanan massal yang dilaksanakan di kedua masjid tersebut, maka mulai tahun 2019 khitanan massal akan diadakan sendiri disekitar rumah dakwah Aisyiyah ranting Ulujami agar lokasi dan segala persiapannya lebih dekat dan efisien.

Terkait dengan sumber dana untuk kegiatan ini, salah seorang aktifis dakwah Aisyiyah, menjelaskan:

"Untuk mendanai aktivitas kesehatan ini, kami membuat proposal meminta bantuan kepada para aghniya (orang yang secara finansial dicukupkan dan potensial menjadi donatur) melalui bu Hj Rachmi, untuk diteruskan kepada relasi-relasi beliau yang memiliki toko farmasi agar membantu Aisyiyah dengan cara memberikan atau menyediakan obat-obatan yang diperlukan, atau kepada donatur lain berupa dana finansial dan lain sebagainya [untuk mendukung terselenggaranya kegiatan pelayanan kesehatan ini]." (Rinda, aktifis dakwah, Jakarta)

Adapun kegiatan sosial yang dilakukan oleh para aktifis perempuan ini meliputi Bakti Sosial yang terkenal disebut dengan baksos, santunan yatim, dhuafa dan fakir miskin dan lain sebagainya. Seorang pengurus dan telah menjadi anggota Aisiyah sejak tahun 2012, menuturkan dalam wawancaranya:

"Kegiatan dakwah yang dirancang di ranting Ulujami antara lain adalah mengadakan dakwah berjamaah baik secara bil-lisan maupun berdakwah sosial bil-haal, baksos, santunan yatim, dhuafa dan fakir miskin dan lain sebagainya. Menurut pengamatan saya selama bergabung dengan komunitas dakwah ini, kegiatan yang paling diminati oleh masyarakat atau oleh jemaah pengajian Aisiyah Ranting Ulujami adalah kajian keagamaan dan Bakti Sosial (baksos)" (Rifa, Jakarta).

Lebih lanjut, Ketua Aisyiyah Ranting Ulujami periode sebelumnya menjelaskan tentang tujuan, bentuk kegiatan dan waktu dari kegiatan diatas:

"Didalam struktur kepengurusan Aisyiyah ranting kami, ada divisi-divisi, salahsatunya yang bernama Majelis Counseling, MKS yang mengurusi baksos seperti pengobatan kesehatan publik gratis yang dilaksanakan tiga bulan sekali pada minggu ke-4, lalu santunan Yatim kepada 45 anak. Pada setiap ajaran baru, bagi yang tidak mempunyai pakaian seragam, kami juga membantu membelikan mereka seragam sekolah. Selain seragam sekolah, kami juga membelikan buku-buku dan keperluan sekolah lainnya. Pada hari lebaran, kami juga turut membantu membelikan keperluan lebaran mereka." (Rina, Ibu Rumah tangga, Jakarta).

Para aktifis dakwah Aisyiyah Ulujami juga membantu meringankan biaya para siswa dari tingkat TK s/d SLTA. "Kami berikan Rp 50.000 per-anak setiap awal bulan. Kendati mereka 
belum masuk TK, tapi nama mereka sudah terdaftar di sini [Aisyiyah ranting Ulujami], maka akan kami santuni juga mereka," kata Rina, salahsatu ketua Aisyiyah periode sebelumnya di kediamannya.

Selain kegiatan diatas, Aisyiyah Ulujami juga menyelenggarakan pemotongan hewan kurban yang diadakan di halaman rumah salahsatu pengurus Aisyiyah. Hal ini menurut mereka, merupakan bagian dari memperkuat kesadaran beragama dan amal social serta berbagi bagi masyarakat luas yang dicontohkan melalui praktek (bukan hanya melalui pembahasan ayat didalam sesi pengajian atau majlis taklim). Bagi mereka, penting keseimbangan antara dakwah bil lisan dengan dakwah bil hal (dakwah bil qudwah hasanah) didepan masyarakat luas. Dakwah bil hal (dakwah bil qudwah hasanah) dalam konteks masyarakat urban yang plural sangat cocok dan berpengaruh kepada perubahan prilaku. Hal ini terjadi karena tingkat literasi agama di masyarakat masih ada kesenjangan (gap), sehingga bagi masyarakat yang tingkat literasi agamanya masih rendah, contoh prilaku secara langsung dari pimpinan dan anggota Aisyiyah, lebih efektif daripada dijelaskan dalil dari Al-Qur'an dan Hadis-hadis Nabi.

Terkait dengan sumber biaya untuk semua kegiatan diatas, selama ini Aisyiyah belum pernah menerima bantuan keuangan baik dari internal Muhammadiyah Ranting Ulujami ataupun dari Muhammadiyah cabang, daerah atau pusat. Menurut penuturan ketua dan pengurus Aisyiyah, semua kegiatan Aisiyah Ranting Ulujami didanai 'dari kantong sendiri', karena mereka juga tidak mendapatkan dana dari lembaga-lembaga, instansi-instansi ataupun institusi lainnya. "Aisyiyah Ulujami tidak pernah menerima bantuan dari luar. Semua kegiatan didanai dari kita dan untuk kita. Kami membiayai semua aktivitas Aisiyah Ulujami dengan gotong royong dari dana kami sendiri” (Rina, Jakarta).

Rina kemudian menjelaskan bahwa sejak 7 tahun terakhir sampai sekarang (2012-2019), Muhammadiyah dan Aisyiyah ranting Ulujami mampu menghimpun dana sekitar Rp 30 juta pertahun. Ada donatur dermawan yang bersedia secara rutin menginfakkan sebagian rezeki Allah SWT kepada mereka itu untuk mendanai santunan yatim, dhuafa, fakir miskin setiap tahun dan setiap ada event-event hari besar Islam. Dengan uang tersebut, Aisyiyah Ulujami juga mampu membiayai puluhan siswa-siswi tingkat TK sampai SMP/MTs yang dibayarkan setiap awal bulan.

Dalam observasi penulis, inklusifitas kegiatan Aisyiyah sangat terlihat dalam kegiatan pendidikan, social, dan dakwah. Para peserta, anggota dan jemaah pengajian serta warga yang mengikuti pengajian Aisiyah Ulujami adalah warga masyarakat umum yang berasal dari berbagai latar belakang asal daerah/suku dan organisasi keagamaan yang kebetulan tinggal (ada yang 
memang permanen, ada juga yang sementara karena pekerjaan) di sekitar Ulujami. Jamaahnya berbaur dan berinteraksi satu sama lain dengan warga yang memiliki afiliasi organisasi keagamaan yang berbeda, tidak hanya orang-orang dengan latar belakang organisasi Aisyiyah saja.

\section{Kerukunan Sosial dan Tradisi Shilaturrahim}

Selain kegiatan dakwah, Aisyiyah Ulujami juga terlihat cukup aktif dan intens bershilaturrahim, baik secara formal karena ada momen hari besar keagamaan atau secara informal karena ada kegiatan kekerabatan atau kedekatan lingkungan rumah (tetangga). Karena masyarakat Betawi sangat identik dengan kegiatan shilaturrahim, maka Aisyiyah di ranting Ulujami juga memiliki ciri khas Shilaturahhim antar anggota keluarga, antar tetangga, antar kolega, antar teman, dan antar kenalan. Shilaturahim didalam masyarakat Ulujami terlihat dalam berbagai acara, baik formal, non-formal ataupun dalam kegiatan sehari-hari.

Shilaturahim Asiyiyah ditengah masyarakat urban Betawi yang terkait dengan hari besar keagamaan dan sudah terjadwal sejak jauh-jauh hari misalnya terjadi ketika hari raya 'Iedain yaitu Idul Fitri dan Idul Adha. Adapun yang tidak resmi karena tidak terkait dengan hari besar keagamaan dan tidak terjadwal atau bisa terjadi kapan saja misalnya ketika sanak saudara ada yang menikah (walimatul 'ursy), melaksanakan haji (walimatus safar), sunatan (walimatul khitan), kehamilan, melahirkan, juga syukuran atas berbagai pencapaian dalam hidup salahsatu anggota keluarga seperti wisuda anak, mendapatkan pekerjaan, karir naik/meningkat, dan lain lain.

Sedangkan shilaturahim lain yang biasa dilaksanakan oleh para anggota dan jamaah Aisyiyah di Ulujami yang sering terjadi dalam kegiatan sehari-hari, seperti arisan keluarga yang bersifat mingguan dan bulanan. Bahkan salahsatu anggota masyarakat dan partisipan kegiatan Aisyiyah Ulujami mengatakan ia mengikuti lebih dari tiga kumpulan arisan dalam sebulan. Jika, ia mengikuti paling tidak 3 kelompok arisan, maka bisa dibayangkan pertemuan antar keluarga, tetangga atau kolega bisa terjadi beberapa kali dalam seminggu atau sebulannya karena ada ragam kegiatan bersama setiap minggunya.

Shilaturahim yang terjadi dalam kegiatan sehari-hari yang lain misalnya, saling berkunjung ke rumah saudara atau tetangga untuk bertukar kabar ataupun berkirim makanan/minuman menjadi fenomena yang bisa sering kita saksikan dalam keseharian hidup ibu-ibu Aisyiyah di Betawi.

Oleh karena itu, bagi Aisyiyah Ulujami suasana shilaturrahim tidak hanya terjadi ketika hari $\mathrm{H}$ idul Fitri, tetapi juga jauh sebelumnya dan setelahnya dalam keseharian mereka sering shilaturahim dalam berbagai acara dengan berbagai lapis persaudaraan, ketetanggaan dan 
pertemanan. Tradisi silaturahmi antar sesama warga yang dijaga oleh komunitas Aisyiyah Ulujami tentu dapat meningkatkan harmoni social dan kohesifitas sosial. Mereka saling bertemu dalam berbagai kegiatan, saling mengunjungi dan menjabat erat tangan serta larut dalam suasana kegembiraan dan kedekatan emosional satu sama lain. Kegiatan shilaturahim dalam berbagai kegiatan dakwah Aisyiyah ini dapat mereduksi kesenjangan satu orang dengan orang lainnya akibat minimnya interaksi dan komunikasi di antara mereka.

Pada dasarnya silaturahmi yang dibangun komunitas Asiyiyah ranting Ulujami merupakan bagian dari modal sosial. Modal sosial sebagai sikap saling percaya antar sesama warga (interpersonal trust) dan jaringan keterlibatan dalam kehidupan kewargaan (civic engagement) (Putnam, 2002). Lebih jauh modal sosial dapat dijabarkan sebagai kehendak baik, persahabatan, simpati, dan hubungan sosial di antara individu dan keluarga yang menciptakan unit sosial. Tingkat interpersonal trust yang baik akan memberi kontribusi terhadap kohesifitas sosial dalam sebuah masyarakat. Sebaliknya, sikap saling tidak mengenal, curiga, menyimpan dendam dan memusuhi dapat merusak dan memperburuk relasi sosial.

Gambaran berbagai kegiatan pelayanan social, kesehatan, pendidikan yang diselenggarakan oleh Aisyiyah Ulujami dengan tidak mempersoalkan status sosial dan etnisitas dari masing-masing anggota masyarakat yang ingin terlibat dan menerima manfaat dari kegiatankegiatan tersebut seyogyanya adalah tujuan ideal dalam beragama seperti yang diajarkan Islam.

\section{KESIMPULAN}

Dakwah komunitas dakwah perempuan (Aisyiyah) ditingkat akar rumput di Ranting Ulujami Jakarta Selatan cukup beragam, mencakup bidang pendidikan, pelayanan kesehatan, pelayanan social dan lain-lain. Praktek beragam kegiatan dakwah di tingkat ranting cukup inklusif, terbuka dan dirasakan manfaatnya oleh masyarakat luas, bukan hanya dirasakan oleh anggota dan simpatisan Aisyiyah. Hal ini setidaknya yang selama ini sudah dan sedang dipraktekan oleh ranting Aisyiyah Ulujami Jakarta Selatan.

Aktifitas dakwah yang dilakukan oleh pengurus-perngurusnya menunjukkan bahwa mereka mengajak serta seluruh elemen masyarakat untuk bergabung dalam kegiatan mereka. Mereka tidak menggelar kegiatan yang tertutup untuk masyarakat non-Aisyiyah. Mereka justru sengaja menyasar berbagai kalangan agar manfaat kegiatan bisa dirasakan oleh masyarakat luas. Hal ini tentu saja diinspirasi oleh ideology dan visi dakwah Muhamamdiyah yang rumusan pandangan keagamaannya bersifat inklusif, solutif dan moderat. Begitu juga praktek dakwah yang 
dilakukan oleh Aisyiyah dan Muhammadiyah di level paling atas (Pimpinan Pusat Aisyiyah/PPA dan Pimpinan Pusat Muhammadiyah/PPM) menunjukkan moderatisme dan inklusifisme pimpinan terhadap beberapa isu public kontemporer dan terhadap pluralitas di masyarakat.

Amal soleh dan amal social menjadi kata kunci gerakan dakwah komunitas Aisyiyah di Ranting Ulujami. Berbagai kegiatan dakwah mereka dilandasi oleh spirit memberikan amal soleh dan menjalankan amal social sesuai pesan KH Ahmad Dahlan ketika mengimplementasikan surat Al-Maun. Aisyiyah Ulujami dalam menjalankan peran dakwahnya lebih sering terlihat merespon setiap persoalan public dengan berorientasi pada kemaslahatan hidup sosial-keagamaan, kemanusiaan dan kebangsaan di Indonesia. Mereka melalui dakwahnya terus melakukan upaya sosialisasi dan diseminasi pandangan keagamaan moderat, inklusif serta terus berkontribusi memberikan solusi atas kebutuhan dan persoalan yang dirasakan masyarakat luas.

Selain itu, komunitas dakwah perempuan Aisyiyah ini juga turut menciptakan kehidupan masyarakat yang harmonis di perkotaan yang cenderung sangat plural. Hal itu adalah hasil dari berbagai kegiatan inklusif yang mereka rancang, selain kentalnya budaya shilaturrahim mengikat dan memperkuat persaudaraan, pertemanan dan ketetanggaan. Aisyiyah Ranting Ulujami menyadari bahwa kehidupan social yang harmonis menjadi sebuah keharusan untuk terus dirawat dan diperjuangkan. Mengingat bahwa Indonesia itu bangsa yang majemuk dan Jakarta adalah ibukota yang sangat plural dan dinamis, serta rentan terhadap konflik social karena tekanan social dan ekonomi begitu tinggi. Sebagai saran, penting kiranya berbagai komunitas di masyarakat di perkotaan didorong terus agar merancang kegiatan yang bisa menopang kemajemukan masyarakat urban dan membangun suasana yang harmonis dan nyaman untuk semua orang dari berbagai golongan/elemen masyarakat.

\section{DAFTAR PUSTAKA}

De Los Herros, S. 2009. Linguistic Pluralism or prescripticism? A CDA of language ideologies in Talento; Peru's official textsbooks for the first-year of high school. Linguistic and Education, 20, 172-199.

Dewi, K.H. 2008. Perspective versus Practice: Women Leadership in Muhammadiyah. Sojourn, 23(2).

Dzuhayatin, Ruhaini. 2015. Rezim Gender Muhammadiyah; Kontestasi Gender, Identitas, dan Eksistensi. Yogyakarta: Suka Press. 
Fuad, A.F.N. 2010. Aisyiyah di Ruang Publik. Jurnal Ma'arif, 5 (1).

Fuad, A.F.N. 2018. Purifikasi dan Modernisasi Dakwah Muhammadiyah; Studi Kasus Muhammadiyah Ranting Ulujami Jakarta Selatan, Jurnal Pendidikan Islam, 9 (1).

Fuad, A.F.N. 2020. Ideologi Nyai Walidah dan Pendidikan Perempuan. https://rahma.id/ideologinyai-walidah-dan-pendidikan-perempuan/

Halliday, M.A.K. 1978. Language as Sosial Semiotic. London: Edwarld Arnold.

Hamka. 2014. Buya Hamka Berbicara Tentang Perempuan. Depok: Gema Insan

Hidayat, Syamsul. dkk (eds). 2012. Studi Muhammadiyah: Kajian Historis, Ideologis, dan Organisatoris. Surakarta: Universitas Muhammadiyah Surakarta.

LPCR PP Muhammadiyah. 2012. Peta Kondisi Cabang dan Ranting Muhammadiyah di Provinsi DKI Jakarta.Yogyakarta: LPCR PP Muhammadiyah.

Lubis, Arya. 1993. Pemikiran Muhammadiyah dan Muhammad Abduh: Suatu Studi Perbandingan. Jakarta: Bulan Bintang.

Ma'arif, Syamsul. 2009. Gerakan Muhammadiyah Berbasis Masjid dan Jamaah, Yogyakarta; Majelis Pendidikan Kader PP Muhammadiyah.

Majelis Tarjih dan Tajdid Pimpinan Pusat Muhammadiyah, 2012. Adabul Mar'ah fil Islam. Suara Muhammadiyah, Yogyakarta.

PP Aisyiyah. 2012. Isu-isu Perempuan dan anak Perspektif Tarjih Muhammadiyah Menuju Keluarga Sakinah, Yogyakarta, STIKES Asiyiyah.

PP Muhammadiyah. 2015. Program Muhammadiyah 2015-2020: Gerakan Pencerahan Menuju Indonesia Berkemajuan.

Pranawati, R. 2006. Women Leadership within the Elite Members of Muhammadiyah: Post the $45^{\text {th }}$ National Conference 2005. Thesis, UIN Syarif Hidayatullah Jakarta.

Ro'fah, 2016. Posisi dan Jati Diri 'Aisyiyah: Perubahan dan Perkembangan 1917-1998. Yogyakarta: Suara Muhammadiyah.

Syamsiyatun, S. 2016. Pergolakan Putri Islam: Perkembangan Wacana Jender dalam Nasyiatul 'Aisyiyah 1965-2005. Suara Muhammadiyah.

Syamsuddin, Din. 2009. Gerakan Muhammadiyah Berbasis Masjid dan Jamaah, Yogyakarta, Majelis Pendidikan Kader PP Muhammadiyah. 
UNWOMEN. Women and The SDGs: SDG 5 Gender Equality. www.unwomen.org.

Zamah Sari. 2013. Kemuhammadiyahan. Jakarta: UHAMKA Press. 